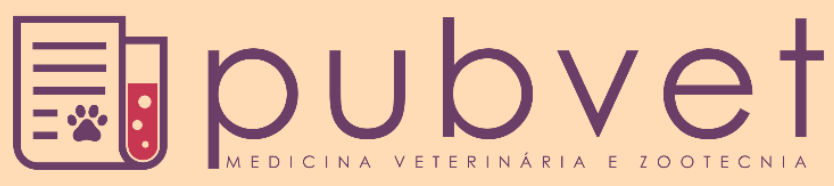

https://doi.org/10.31533/pubvet.v13n11a444.1-8

\title{
Pênfigo foliáceo canino: relato de caso
}

\author{
Adjanna Karla Leite Araujo ${ }^{10}$, Adriana Leão de Carvalho Lima Gondim* ${ }^{2 *}$

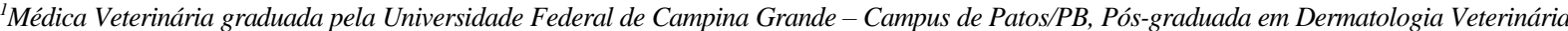 \\ de Pequenos Animais pelas instituições Qualittas - Universidade Castelo Branco e Equalis, Especialização em Parasitologia Clínica e Saúde Pública \\ pela UPE, Mestrado em Ciências Veterinárias pela Universidade Estadual do Ceará e pelo Centro de Pesquisa Aggeu Magalhães - FIOCRUZ-PE. \\ ${ }^{2}$ Médica Veterinária graduada pela Universidade Federal Rural de Pernambuco - UFRPE, Pós-graduada em Dermatologia Veterinária de \\ Pequenos Animais pela instituição Qualittas - Universidade Castelo Branco. \\ *Autor para correspondência, E-mail: $\underline{\text { adrianalclg@gmail.com }}$
}

Resumo. As doenças autoimunes da pele são decorrentes da produção de anticorpos ou da ativação de linfócitos contra os próprios componentes da pele, sendo pouco frequentes em pequenos animais, porém mais frequente em cães do que em gatos. Clinicamente, o pênfigo foliáceo caracteriza-se por lesões alopecias, pustulares e crostosas. Entretanto, esses quadros são um desafio para o diagnóstico clínico, pois estão relacionados a um grande número de dermatopatias observadas nos animais de companhia. O diagnóstico da doença é feito através da observação do histórico, sinais clínicos do paciente e exames complementares como citologia da pele lesionada e exame histopatológico das lesões. O tratamento é feito com imunossupressores, com o objetivo de suprimir a resposta imunológica do paciente. Como o tratamento é longo, o animal deve ser acompanhado com exames laboratoriais a fim de se avaliar os efeitos colaterais relacionados ao uso prolongado dos imunossupressores. O presente artigo teve como objetivo relatar um caso de Pênfigo Foliáceo, em um paciente da espécie canina, fêmea, da raça buldogue inglês com cinco anos de idade que apresentou resposta rápida ao tratamento com uso de corticoides. O pênfigo foliáceo deve ser incluído como suspeita clínica em pacientes com lesões cutâneas, principalmente pustulares, pois um diagnóstico correto e precoce é fundamental para o sucesso do tratamento.

Palavras chaves: dermatologia, doença autoimune, prurido intenso, imunossupressores.

\section{Canine foliaceous Pemphigus: case report}

Abstract. Autoimmune diseases of the skin are due to antibody production or activation of lymphocytes against their own skin components, and are uncommon in small animals, but more common in dogs than in cats. Clinically, pemphigus foliaceus is characterized by alopecic, pustular and crusted lesions. However, these conditions are a challenge for the clinical diagnosis, as they are related to a large number of dermatopathies observed in companion animals. The diagnosis of the disease is made by observing the history, clinical signs of the patient and complementary exams such as cytology of the injured skin and histopathological examination of the lesions. The treatment is done with immunosuppressants, aiming to suppress the patient's immune response. Because the treatment is long, the animal should be accompanied with laboratory tests to assess the side effects related to prolonged use of immunosuppressants. The aim of this article was to report a case of Pemphigus foliaceus in a five years old female English bulldog patient who presented rapid response to corticosteroid treatment. Pemphigus foliaceus should be included as a clinical suspicion in patients with mainly pustular skin lesions, since a correct and early diagnosis is essential for the success of treatment

Keywords: dermatology, autoimmune disease, intense itching, immunosuppressants 


\section{Pénfigo canino foliáceo: reporte de caso}

Resumen. Las enfermedades autoinmunes de la piel se deben a la producción de anticuerpos o la activación de linfocitos contra sus propios componentes cutáneos, y son poco frecuentes en pequeños animales, pero son más comunes en perros que en gatos. Clínicamente, el pénfigo foliáceo se caracteriza por lesiones alopécicas, pustulosas y con costras. Sin embargo, estas condiciones son un desafío para el diagnóstico clínico, ya que están relacionadas con una gran cantidad de dermopatías observadas en animales de compañía. El diagnóstico de la enfermedad se realiza mediante la observación del historial, los signos clínicos del paciente y los exámenes complementarios, como la citología de la piel lesionada y el examen histopatológico de las lesiones. El tratamiento se realiza con inmunosupresores, con el objetivo de suprimir la respuesta inmune del paciente. Debido a que el tratamiento es largo, el animal debe ir acompañado de pruebas de laboratorio para evaluar los efectos secundarios relacionados con el uso prolongado de inmunosupresores. El objetivo de este artículo fue reportar un caso de Pénfigo foliáceo en una paciente Bulldog inglés de cinco años que presentó una respuesta rápida al tratamiento con corticosteroides. El pénfigo foliáceo debe incluirse como una sospecha clínica en pacientes con lesiones cutáneas principalmente purulentas, ya que un diagnóstico correcto y temprano es esencial para el éxito del tratamiento.

Palabras clave: dermatología, enfermedad autoinmune, prurito intenso, inmunosupresores

\section{Introdução}

As doenças imunológicas da pele são classificadas em autoimunes ou primárias e imuno-mediadas ou secundárias. As afecções cutâneas imuno-mediadas parecem ser resultantes de um evento imunológico que não age diretamente contra os autos antígenos, não sendo, portanto, a pele o antígeno primário (Scott, 2001). Já as dermatoses cutâneas autoimunes são decorrentes da produção de anticorpos ou da ativação de linfócitos contra os componentes próprios da pele (Val, 2006).

As doenças cutâneas autoimunes são pouco frequentes em cães e gatos (Hill et al., 2006; Jark et al., 2014; Lupion et al., 2017; Scott, 2001; Souza et al., 2009). O pênfigo foliáceo é uma doença autoimune pertencente ao complexo pênfigo, sendo, apesar de rara, a doença autoimune mais frequentemente observada na rotina de atendimento dermatológico veterinário, acometendo várias espécies, sendo mais comum em cães (Macêdo et al., 2008; Medleau et al., 2003; Pereira et al., 2018; Scott, 2001). O Pênfigo foliáceo é a dermatopatia mais comum dentre as doenças que abarcam o complexo pênfigo (Pereira et al., 2018). Nesta afecção são produzidos anticorpos contra os desmossomos, um componente responsável pela adesão dos queratinócitos na epiderme (Gross et al., 2009; Hnilica \& Patterson, 2017). Quando os queratinócitos são destruídos, perdem a sua estrutura normal, promovendo o depósito de imunoglobulinas entre as células levando à acantólise e, consequente formação de vesículas sob o extrato córneo (Balda et al., 2008; Harvey \& Mckeever, 2004; Medleau et al., 2003).

A doença acomete mais frequentemente cães de meia idade (Balda et al., 2008), aparentemente não há predileção por sexo (Balda et al., 2008; Larsson et al., 1998) e tem maior prevalência nas raças Akita, Border Collie, Chow Chow, Dachshund, Dobermann e Terranova (Barbosa et al., 2012), sendo gradualmente progressiva em aproximadamente $75 \%$ dos casos e desenvolvendo-se em menos de 3 meses em 25\% dos casos (Ettinger et al., 2017). Estudos indicam que o pênfigo foliáceo tem causa idiopática, mas pode-se classificar a doença nas formas espontânea, mais comum em cães de raças predispostas como Akita e Chow chow; e induzida por drogas, doenças crônicas e outros fatores, tais como luz ultravioleta, queimaduras, neoplasias, fatores emocionais e nutricionais, entre outros (Balda et al., 2008; Scott, 2001), sendo esta mais frequentemente observada em raças como Labrador, Dobermann e Pinscher (Mueller et al., 2006).

Como diagnósticos diferenciais do pênfigo foliáceo tem-se as demais enfermidades do complexo pênfigo, foliculite bacteriana, leishmaniose cutânea, dermatofitose, diferentes enfermidades seborreicas, piodermite superficial, entre outras afecções cutâneas (Arroyo-Munive et al., 2018; Barbosa et al., 2012; Rosenkrantz, 2004; Scott, 2001). 
Levando-se em consideração que a doença autoimune é uma achada pouco frequente na clínica de pequenos animais, objetivou-se relatar um caso de pênfigo foliáceo canino atendido no Serviço de Dermatologia da Clínica Pelo \& Pele - Dermatologia e Alergologia Veterinária ${ }^{\circledR}$, na cidade de Caruaru, Pernambuco, Brasil.

\section{Relato de caso}

No dia 29 de setembro de 2017 foi atendido no Serviço de Dermatologia da Clínica Pelo \& Pele Dermatologia e Alergologia Veterinária ${ }^{\circledR}$, localizada na cidade de Caruaru, no estado de Pernambuco, um canino da raça Buldogue Inglês, fêmea, com 5 anos de idade e peso de $23,7 \mathrm{~kg}$, apresentando como queixa principal múltiplas lesões cutâneas. O responsável relatou que o animal já havia feito tratamento com alguns antibióticos (cefalexina, amoxicilina e enrofloxacina), além de aplicações de pomadas com mupirocina e xampu a base de peróxido de benzoíla 2,5\% sem nenhuma resposta significativa aos tratamentos. Na ocasião o mesmo ainda relatou que o animal também havia feito tratamento com prednisolona, sendo observada uma pequena melhora no quadro que apresentava, porém com rápida recidiva do quadro. No exame clínico foi observado dermatite úmida aguda, esfoliativa, com presença de eritrodermia, disqueratinização furfurácea (Figura 1A), papiloma labial (Figura 1B), lesões crostosas inflamadas de forma arredondada em todo o corpo do paciente (Figura 1C), além de lesões aciformes ao redor das mamas. Foi ainda observada otite bilateral, hipertrofia dos linfonodos e onicogrifose (Figura 1D).

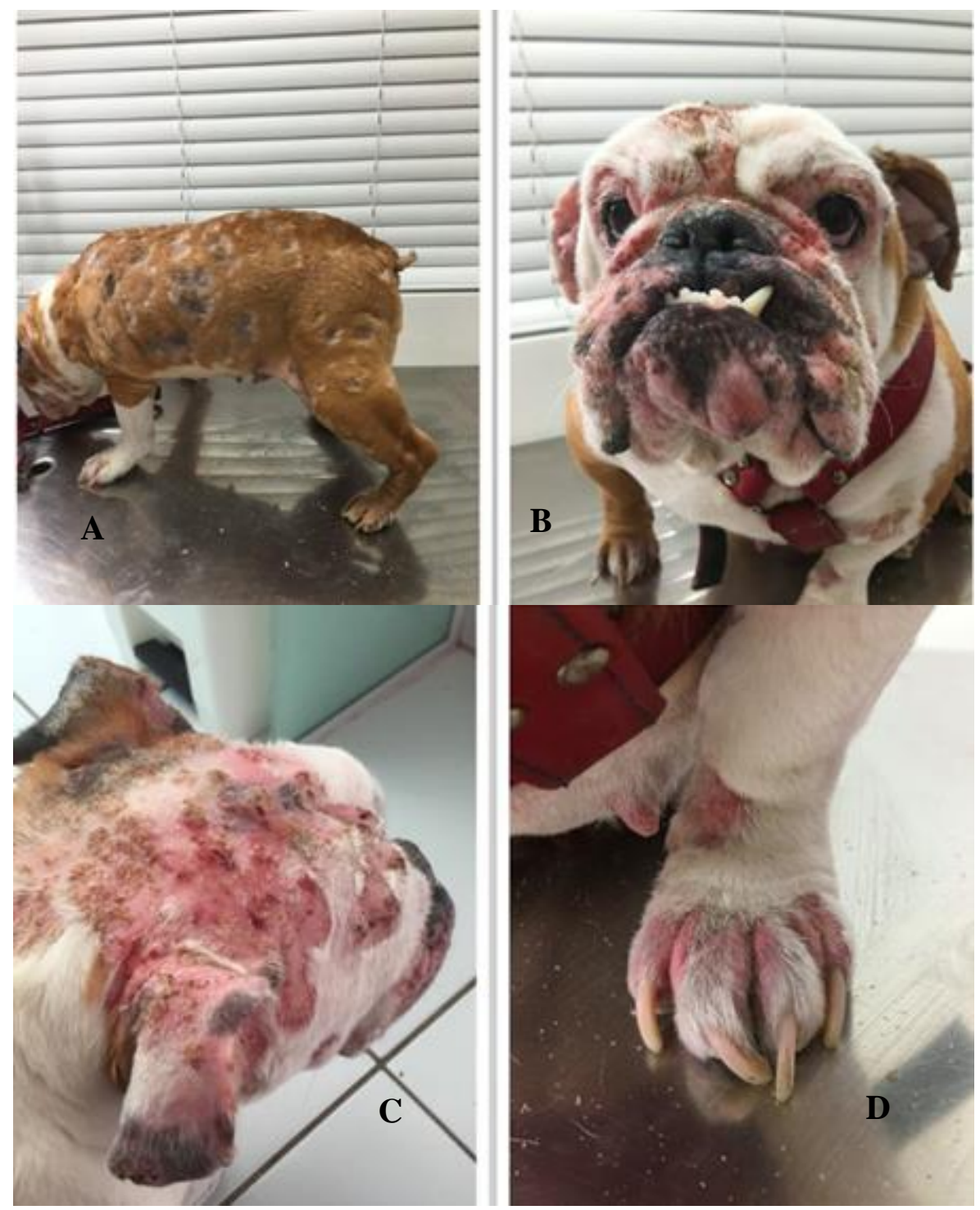

Figura 1. (A): Disqueratinização furfurácea observada no paciente.; (B): Lesões crostosas arredondadas e papiloma labial observados no paciente; (C): Lesões crostosas inflamadas de forma arredondada encontradas no paciente; (D): Onicogrifose. 
Para o tratamento foi prescrito marbofloxacina $\left(\right.$ Marbopet $^{\circledR}$ ) na dose de um comprimido de $82,5 \mathrm{mg}$, a cada 24 horas durante 10 dias, solução spray de betametasona a cada 24 horas sobre as lesões e o paciente foi internado para realização de biópsia de pele. Na ocasião foram também realizadas dosagens bioquímicas, sendo observado aumento na dosagem sérica de fosfatase alcalina (316,0 UI/L), sendo que o valor de referência para a espécie é de 20 a 150 UI/L, sem nenhuma outra alteração significativa nas demais dosagens bioquímicas realizadas. Foi ainda realizado sorologia para Leishmaniose pelo método imunoenzimático (ELISA), sendo o resultado não reagente.

No dia 03 de outubro de 2017 a paciente retornou ao consultório e o tutor relatou que nesse intervalo procurou outro profissional veterinário que ao examinar o paciente com luz fluorescente (luz de wood) havia prescrito além da ração Royal Canin Veterinary Hypoallergenic ${ }^{\circledR}$, itraconazol (ITL ${ }^{\circledR)}$ na dose de $100 \mathrm{mg}$ ao dia, cetoconazol spray Ibasa ${ }^{\circledR}$ e xampu a base de clorexidine e miconazol (Cloresten ${ }^{\circledR}$ ), retirando do protocolo anteriormente prescrito a solução spray de betametasona e mantendo a administração de marbofloxacina (Marbopet ${ }^{\circledR}$ ) na dose recomendada previamente. Nesta ocasião, no exame clínico pôde-se observar eritrodermia ventral generalizada, dermatite úmida aguda, crostas melicéricas em região dorsal disposta em lesões de formato arredondado, alopecia com eritema e crostas em região facial e periocular, além de edema nos quatro membros, otorreia purulenta bilateral, queratose palmoplantar, onicogrifose, ungeíte e diversas pústulas. O tutor relatou ainda que o animal apresentava prurido intenso.

No exame histopatológico feito através da amostra colhida na biópsia de pele realizada anteriormente observou-se dermatite pustular superficial com acantose difusa e paraqueratose focal. Foi também realizada citologia por imprint das lesões, sendo encontrados inúmeros queratinócitos acantolíticos bordeadas por neutrófilos, denominadas de células de Tzanck (Figura 2).

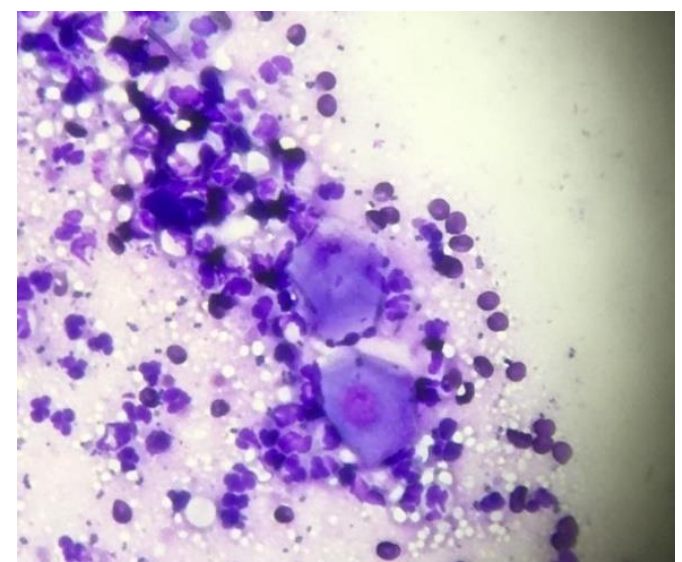

Figura 2. Células de Tzank - Queratinócitos acantolíticos bordeados por neutrófilos observado em exame citológico realizado pela técnica de imprint das lesões (Aumento: 100x).

Observando o quadro clínico do paciente e através das alterações encontradas nesses exames concluiu-se o diagnóstico de pênfigo foliáceo.

Para o tratamento foi orientado ao tutor a continuar a administração da Marboflaxina (Marbopet ${ }^{\circledR}$ ) na dosagem de um comprimido de $82,5 \mathrm{mg}$ uma vez ao dia, sendo ainda prescrito prednisolona $\left(\right.$ Predsin ${ }^{\circledR}$ ) na dosagem de $50 \mathrm{mg}$ uma vez ao dia, durante 30 dias e solução spray de betametasona a cada 24 horas. As demais medicações que o paciente vinha fazendo uso foram suspensas.

No dia 07 de outubro de 2017, poucos dias após o início do tratamento, em novo retorno, observouse uma redução aparente do edema nos membros além de evidente melhora na eritrodermia ventral (Figura 3), sendo percebido controle total do quadro generalizado (Figura 4). A paciente continuou então o tratamento, sem maiores intercorrências e no dia 27 de outubro de 2017 retornou ao consultório para avaliação, apresentando melhora significativa do quadro geral (Figura 5). Na ocasião foi colhida amostra de sangue para dosagem bioquímica sérica, observando-se um aumento na dosagem de fosfatase alcalina (1291,7 UI/L) e foi prescrito vitamina E na dosagem de 400UI, uma vez ao dia, por 30 dias. A partir de então, passou-se ao desmame da dose inicial da prednisolona (Predsin $\left.{ }^{\circledR}\right)$, sendo prescrita a dose 
de 40mg, uma vez ao dia durante 10 dias. O desmame da prednisolona (Predsin ${ }^{\circledR}$ ) foi realizado, diminuindo-se a dose pela metade a cada 10 dias, associando a administração de azatioprima (Imuran ${ }^{\circledR}$ ) na dose de 50mg.

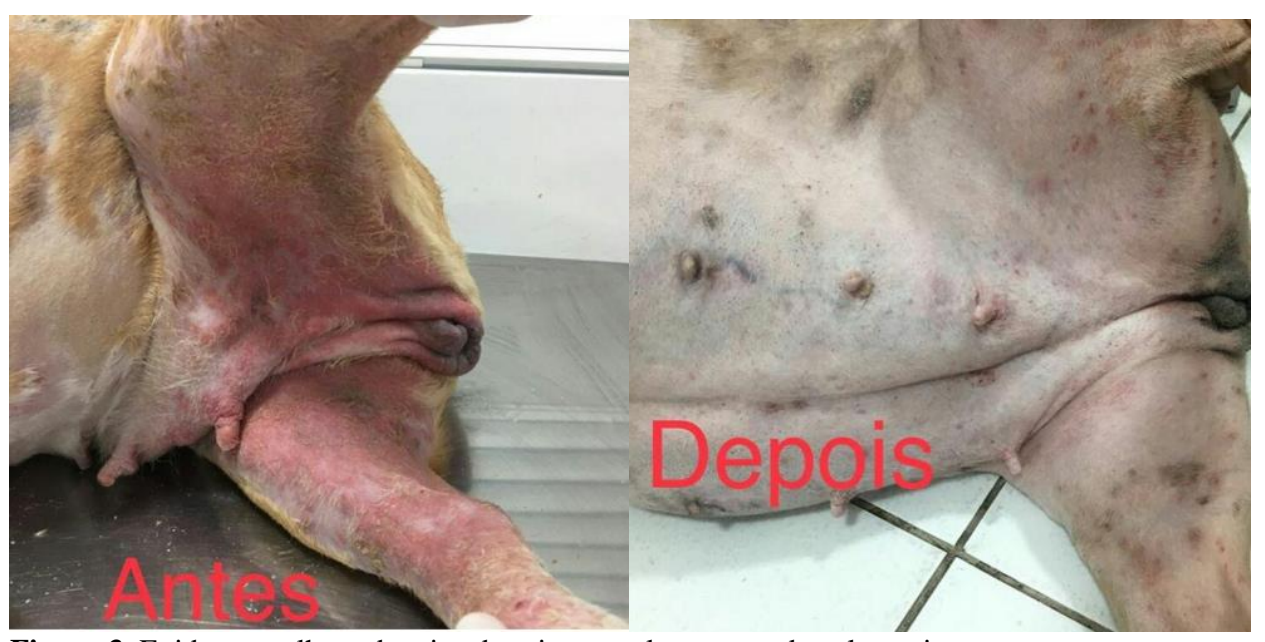

Figura 3. Evidente melhora da eritrodermia ventral apresentada pelo paciente.

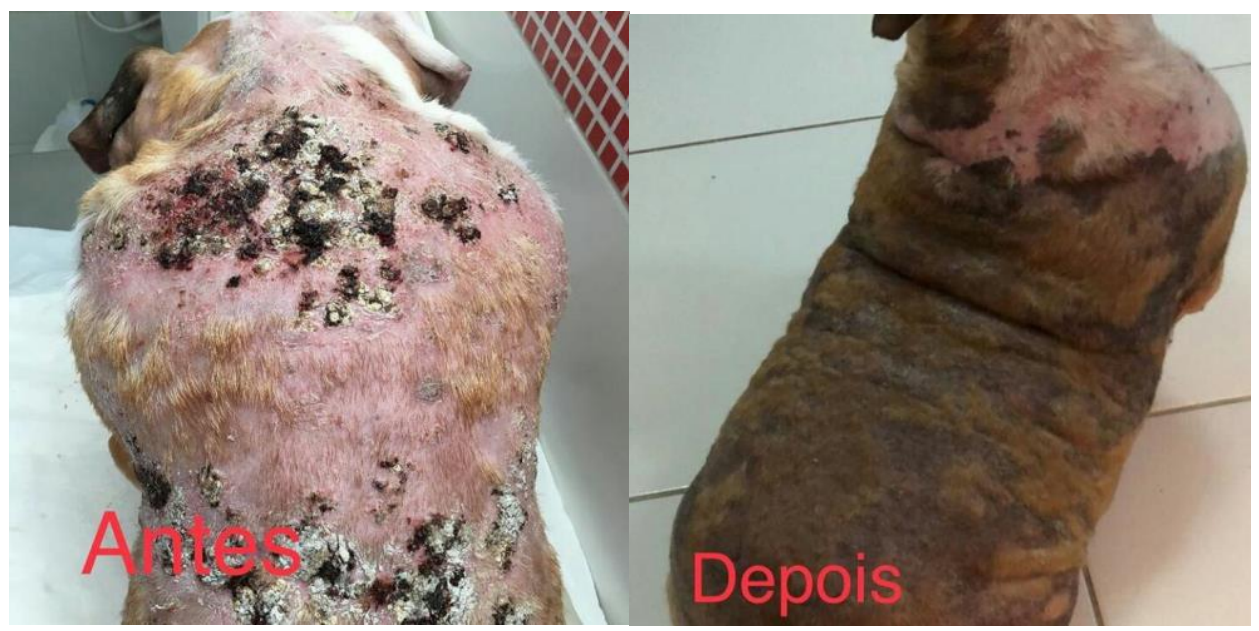

Figura 4. Paciente apresentando controle total do quadro generalizado.

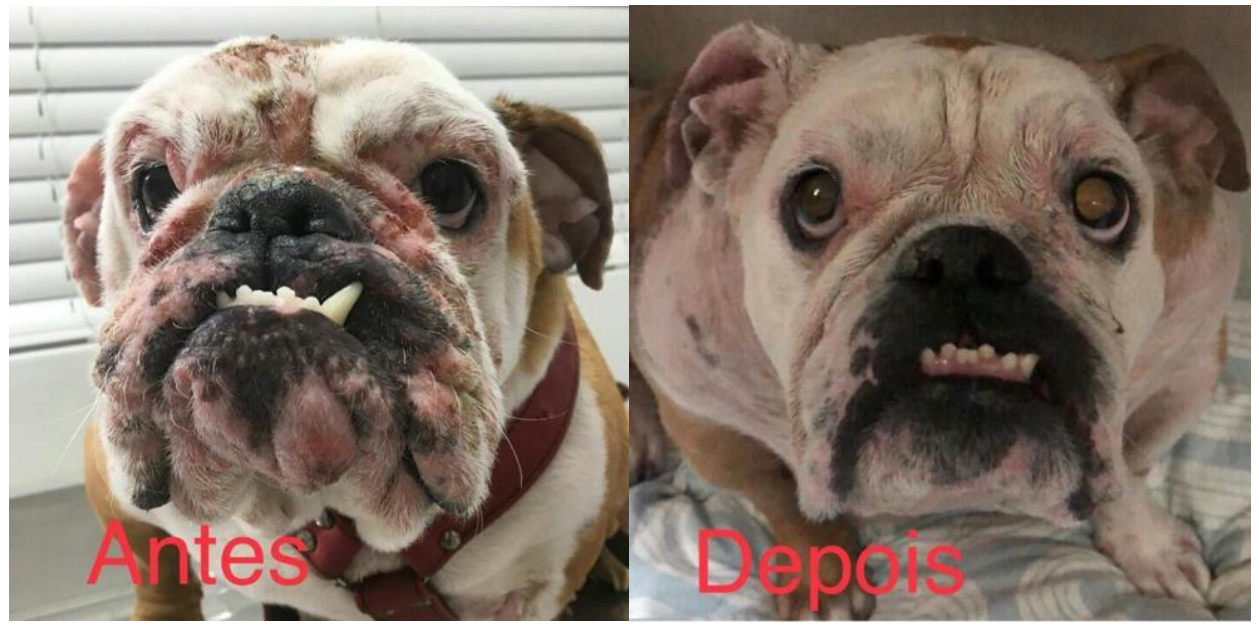

Figura 5. Paciente apresentando melhora significativa do quadro geral.

O paciente passou então a fazer exames periódicos de controle para avaliar possíveis alterações laboratoriais decorrentes de efeitos adversos à prednisolona e à azatriprina. No dia 5 de março de 2018 foram realizadas novas dosagens bioquímicas, sendo ainda observado aumento na concentração sérica de fosfatase alcalina (1.207,3 UI/L) e hemograma no qual se observou como única alteração leucocitose. 
Posteriormente, no dia 9 de Janeiro de 2019, foram repetidos os exames onde foi constatada uma diminuição considerável na dosagem de fosfatase alcalina (167 UI/L) e no hemograma uma leucocitose discreta, sendo então o paciente liberado com dose contínua de $10 \mathrm{mg}$ de prednisolona (Predsin ${ }^{\circledR}$ ) e azatioprima $\left(\operatorname{Imuran}{ }^{\circledR}\right)$ na dose de $50 \mathrm{mg}$, sendo tais medicações administradas em dias alternados, ou seja, um dia administra-se azatioprima $\left(\operatorname{Imuran}^{\circledR}\right.$ ) na dose de $50 \mathrm{mg}$ e no outro dia prednisolona $\left(\right.$ Predsin $\left.^{\circledR}\right)$ na dose de 10mg.

\section{Discussão}

O pênfigo foliáceo é, dentre as dermatopatias autoimunes, a mais encontrada em cães, principalmente naqueles em que enfermidades dermatológicas são erroneamente diagnosticadas, de caráter crônico e não responsivos a tratamentos convencionais (Werner, 1999). O desenvolvimento de tal doença sofre influência de diversos fatores genéticos relacionados à raça do animal e outros, tais como fármacos, alimentação e infecções virais pré-existentes (Tater \& Olivry, 2010). O cão do relato era da raça buldogue inglês, raça não citada como predisposta na literatura consultada e também não tinha histórico de administração de fármacos ou infeções pré-existentes, não sendo, portanto, possível se determinar o que causou a doença no paciente. Segundo Scott (2001) realmente, em muitos casos, a causa do pênfigo foliáceo não pode ser determinada.

Segundo Scott (2001) o pênfigo foliáceo se caracteriza por ser uma dermatite pustular de caráter intraepidérmica, sendo esta a principal diferença quando comparada ao pênfigo humano, onde são observadas vesículas intraepidérmicas. As lesões podem apresentar-se localizadas ou generalizadas e acometem normalmente a face, plano nasal, área auricular, região abdominal e, em alguns casos, os coxins plantares (Barbosa et al., 2012; Frávega, 2012; Mueller et al., 2006), o que foi observado no cão acompanhado no presente relato. Também pode ocorrer comprometimento ungueal, o que ocorreu na paciente do relato, sendo o envolvimento de mucosas e junções mucocutânea bastante raro (Gomez et al., 2004; Mueller et al., 2006). O animal do relato apresentou diversas lesões cutâneas, tendo como lesões principais dermatite úmida aguda, lesões crostosas arredondadas em todo o corpo e eritrodermia ventral, além de alopecia com eritema e crostas na face e região periocular, como descrito na literatura. Prurido de grau moderado a intenso pode estar presente (Barbosa et al., 2012; Larsson et al., 1998). O responsável pelo paciente do relato queixava-se que o mesmo apresentava prurido intenso. Manifestações sistêmicas, como febre, dor, depressão, claudicação, edema, linfoadenopatia e leucocitose neutrofílica podem ocorrer, nas formas graves e generalizadas e é possível ocorrer infecção bacteriana secundária (Larsson et al., 1998; Olivry \& Linder, 2009). O paciente apresentou edema nos quatro membros, hipertrofia dos linfonodos e leucocitose conforme descrito na literatura, apresentando ainda otite purulenta bilateral e queratose palmoplantar. Scott (2001) relata o caso de um cão que além das lesões comumente observadas na doença apresentava crostas, pústulas e áreas de alopecia na região da cauda.

O diagnóstico é realizado com base na história clínica do paciente, nos sinais clínicos da doença, nos resultados de exames complementares tais como citologia e histopatologia das pústulas presentes na pele, onde é possível se evidenciar células acantolíticas soltas na epiderme, esféricas e com hipercromasia nuclear, sendo denominas células de Tzank, além de ausência de bactérias (Balda et al., 2008; Barbosa et al., 2012; Olivry, 2006), achados presentes no exame citológico e histopatológico realizados no caso em relato, porém deve-se analisar a existência de células acantolíticas com precaução, pois tal achado pode estar presente em outras dermatopatias postulares (Val, 2006). Segundo Larsson et al. (1998), Scott (2001) e Balda et al. (2008) o exame histopatológico é o de eleição para o diagnóstico da afecção. Conceição et al. (2004) ressaltam a importância da escolha correta do local da coleta para realização do exame, assim como da utilização da técnica adequada, sendo necessárias diversas coletas, preservando a superfície da lesão.

O tratamento do pênfigo foliáceo é longo e se baseia na administração de drogas imunossupressoras (Barbosa et al., 2012; Olivry, 2006), sendo efetivo o uso de corticoides, tais como prednisona ou dexametasona, por via oral, diariamente, até que a doença esteja controlada, o que dura em média de duas a oito semanas em aproximadamente 50\% dos casos (Arroyo-Munive et al., 2018; Medleau et al., 2003). Para o tratamento do animal em questão, foi utilizado prednisolona, inicialmente na dose de 50 $\mathrm{mg}(2 \mathrm{mg} / \mathrm{kg})$, uma vez ao dia, sendo possível observar melhora significativa do quadro clínico e total 
controle da doença, estando de acordo com Lucarts (2010), segundo o qual, o uso da prednisolona na dose 1-2 mg/kg/diariamente ainda é o fármaco de eleição. Segundo Medleau et al. (2003) e Lucarts (2010) deve-se manter o uso, diminuindo gradativamente a dose, de acordo com as melhoras das lesões do paciente, até que seja atingida a dose mínima efetiva, preferencialmente em dias alternados. No paciente do caso em relato, foi realizado o desmame a cada 10 dias, sempre diminuindo a dose da prednisolona pela metade, até que se passou a administrar continuamente a dose de $10 \mathrm{mg}$ em dias alternados, alternando o uso dessa medicação à administração de azatioprima na dose de $50 \mathrm{mg}$, ou seja, em um dia administrava-se a predinisolona e no outro a azatioprima.

Segundo Tóth \& Jonkman (2001), princípios ativos tais como azatioprina, ciclosporina, tacrolimus, tetraciclina e nicotinamida também podem ser utilizadas. A única desvantagem são as complicações pelo uso prolongado como poliúria, polidipsia, infecções recorrentes do trato urinário inferior, entre outros (Patel \& Forsythe, 2011) o que ocorreu com o paciente do caso em relato. Deve-se sempre considerar possíveis efeitos colaterais como anemia, sangramento gastrointestinal e hepatotoxicidade, além da potencial ocorrência de pancreatite aguda relatados por outros autores (Mueller et al., 2006; Rosenkrantz, 2004). No acompanhamento laboratorial da paciente do caso relatado observou-se leucocitose e aumento da concentração sérica da fosfatase alcalina durante todo o tratamento e após o mesmo. Mueller et al. (2006) recomendam a realização de exames periódicos de função renal e hepática, o que foi feito no caso relatado.

O pênfigo foliáceo ainda é um grande desafio para os médicos veterinários, pois mesmo com os avanços no diagnóstico e tratamento das dermatopatias, a etiologia dessa afecção ainda continua sendo pouco elucidada e, além disso, a diversidade de fatores associados predispõe às falhas terapêuticas e recidivas (Abreu et al., 2014).

\section{Conclusão}

O pênfigo foliáceo, apesar de ser um achado raro na rotina clínica de pequenos animais, deve ser sempre observado como diagnóstico diferencial naqueles animais que apresentam lesões dermatológicas, principalmente quando não responsivas a tratamentos anteriormente realizados. $\mathrm{O}$ exame histopatológico é o exame de eleição para que seja feito o diagnóstico da doença, sendo o exame determinante para elucidação do diagnostico no caso relatado. Com o diagnóstico feito de modo adequado, o tratamento com corticoide é bastante eficaz para o controle da doença.

\section{Referências bibliográficas}

Abreu, C. R., Ondani, A. C., Parpinelli, A. C., Pereira, L. F. \& Dias, F. G. G. (2014). Pênfigo foliáceo canino refratário ao tratamento com corticoide sistêmico: relato de caso. Enciclopédia Biosfera, 10(18):2279 - 2290.

Arroyo-Munive, Y. J., Hincapié-Gutiérrez, L. C. \& Claudia, M. (2018). Diagnóstico de pénfigo foliáceo en un Pinscher. Reporte de un caso. Revista Veterinaria y Zootecnia, 12(2):62-70.

Balda, A. C., Otsuka, M., Larsson Júnior, C. E., Michalany, N. S. \& Larsson, C. E. (2008). Pênfigo foliáceo canino: estudo retrospectivo de 43 casos clínicos e terapia (2000-2005). Pesquisa Veterinária Brasileira, 28387-392.

Barbosa, M. V. F., Fukahori, F. L. P., Dias, M. B. M. C. \& Lima, E. R. (2012). Patofisiologia do pênfigo foliáceo em cães: revisão de literatura. Medicina Veterinária, 6(3):26-31.

Conceição, L., Loures, F., Clemente, J. \& Fabris, V. (2004). Biópsia e histopatologia da pele: um valioso recurso diagnóstico na dermatologia-revisão-parte 1. Clínica Veterinária, 9(52):28-40.

Ettinger, S. J., Feldman, E. C. \& Cote, E. (2017). Textbook of Veterinary Internal Medicine-eBook. USA: Elsevier Health Sciences.

Frávega, R. (2012). Caso clínico: Pénfigo foliáceo inducido por drogas; un caso asociado a solución tópica. Hospitales Veterinarios, 441-46.

Gomez, S. M., Morris, D. O., Rosenbaum, M. R. \& Goldschmidt, M. H. (2004). Outcome and complications associated with treatment of pemphigus foliaceus in dogs: 43 cases (1994-2000). Journal of the American Veterinary Medical Association, 224(8):1312-1316. 
Gross, T. L., Ihrke, P. J., Walder, J. E. \& Affolter, K. V. (2009). Doenças de pele do cão e do gato: diagnóstico clínico e histopatológico. São Paulo: Roca.

Harvey, R. G. \& Mckeever, P. J. (2004). Manual colorido de dermatologia do cão e do gato: diagnóstico e tratamento. São Paulo, Brasil: Revinter.

Hill, P. B., Lo, A., Eden, C. A. N., Huntley, S., Morey, V., Ramsey, S., . . Taylor, M. D. (2006). Survey of the prevalence, diagnosis and treatment of dermatological conditions in small animals in general practice. Veterinary Record, 158(16):533-539.

Hnilica, K. A. \& Patterson, A. P. (2017). Autoimmune and immune-mediated skin disorders. In K. A. Hnilica \& P. A.P. (Eds.), Small animal dermatology: a color atlas and therapeutic guide. Saint Louis, USA: Elsevier.

Jark, P. C., Estanislau, C. d. A., Rondelli, M. C. H., Fabris, V. E., Costa, M. T., Lourenço, M. L. G. \& Machado, L. H. A. (2014). Pênfigo foliáceo em um felino: relato de caso. Veterinária e Zootecnia, 21(4):543-549.

Larsson, C. E., Lucas, R., Otsuka, M. \& Michalany, N. S. (1998). Pênfigo foliáceo em cães-primeiras descrições em São Paulo: relato de casos. Clínica Veterinária, 3(13):28-32.

Lucarts, L. E. B. (2010). Avaliação de exeqüibilidade e da efetividade da determinação de anticorpos séricos pela IFI, em cães acometidos por pênfigo foliáceo na pré e trans-terapia. Universidade de São Paulo, São Paulo, Brasil.

Lupion, C. G., Pino, E. H. M., Silveira, E., Stefanello, C. R., Baretta, L. T. \& Gerardi, D. G. (2017). Pênfigo foliáceo em um gato de oito meses de idade: possível reação cutânea adversa a fármacos? Acta Scientiae Veterinariae, 451-5.

Macêdo, J. T. S. A., Riet-Correa, F., Dantas, A. F. M. \& Simões, S. V. D. (2008). Pênfigo foliáceo em cabra Boer. Ciência Rural, 38(9):2633-2635.

Medleau, L., Hnilica, K. A. \& Fagliari, G. S. (2003). Dermatologia de pequenos animais: atlas colorido e guia terapêutico. São Paulo: Roca.

Mueller, R. S., Krebs, I., Power, H. T. \& Fieseler, K. V. (2006). Pemphigus foliaceus in 91 dogs. Journal of the American Animal Hospital Association, 42(3):189-196.

Olivry, T. (2006). A review of autoimmune skin diseases in domestic animals: I-superficial pemphigus. Veterinary Dermatology, 17(5):291-305.

Olivry, T. \& Linder, K. E. (2009). Dermatoses affecting desmosomes in animals: a mechanistic review of acantholytic blistering skin diseases. Veterinary Dermatology, 20(5-6):313-326.

Patel, A. \& Forsythe, P. J. (2011). Dermatologia em pequenos animais. Rio de Janeiro: Elsevier Brasil.

Pereira, A. L., Nicchio, B. O., Santos, L. M., Lima, D. T., Amorim, J. L. d. S. B., Silva, I. G. \& Carneiro, R. L. (2018). Pênfigo foliáceo em um cão jovem sem raça definida: relato de caso. PUBVET, 12(9):1-7.

Rosenkrantz, W. (2004). Pemphigus: current therapy. Veterinary Dermatology, 15(2):90-98.

Scott, D. W. (2001). Immune-mediated skin disorders. Philadelphia, USA: W.B. Saunders.

Souza, T. M., Fighera, R. A., Schmidt, C., Réquia, A. H., Brum, J. S., Martins, T. B. \& Barros, C. S. L. (2009). Prevalência das dermatopatias não-tumorais em cães do município de Santa Maria, Rio Grande do Sul (2005-2008). Pesquisa Veterinaria Brasileira, 29(2):157-162.

Tater, K. C. \& Olivry, T. (2010). Canine and feline pemphigus foliaceus: improving your chances of a successful outcome. Veterinary Medicine, 105(1):18-30.

Tóth, G. G. \& Jonkman, M. F. (2001). Therapy of pemphigus. Clinics in Dermatology, 19(6):761-767.

Val, A. C. (2006). Doenças cutâneas autoimunes e imunomediadas de maior ocorrência em cães e gatos: revisão de literatura. Clínica Veterinária, 6068-74.

Werner, A. H. (1999). Recognizing and treating discoid inpus erythematosus and pemphigus foliaceus in dogs. Veterinary Medicine, 90955-966.

Recebido: 3 de outubro, 2019.

Aprovado: 17 de novembro, 2019.

Publicado: 17 de dezembro, 2019.

Licenciamento: Este artigo é publicado na modalidade acesso aberto sob a licença Creative Commons Atribuição 4.0 (CC-BY 4.0), a qual permite uso irrestrito, distribuição, reprodução em qualquer meio, desde que o autor e a fonte sejam devidamente creditados. 